\title{
PENGARUH KELOMPOK PENDUKUNG AIR SUSU IBU (KP-ASI) TERHADAP PERILAKU PEMBERIAN ASI EKSKLUSIF DAN STATUS GIZI BAYI 6-12 BULAN
}

\author{
The Influence of Breastfeeding Support Group (BSG) to Exclusive Breastfeeding Practice and \\ Nutrition Status of Infants Aged 6-12 Months \\ Nur Hikmahwati $^{\text {* }}$, Lailatul Muniroh ${ }^{2}$ \\ ${ }^{1}$ Program Studi Ilmu Gizi, Fakultas Kesehatan Masyarakat, Universitas Airlangga, Surabaya \\ ${ }^{2}$ Departemen Gizi Kesehatan, Fakultas Kesehatan Masyarakat, Universitas Airlangga, Surabaya \\ E-mail: imahikmah2@gmail.com
}

\begin{abstract}
ABSTRAK
Air susu ibu menjadi makanan terbaik dan bergizi pada awal kehidupan bagi setiap bayi yang dilahirkan. Kekurangan gizi pada bayi dapat menyebabkan gangguan pertumbuhan dan perkembangan. Capaian ASI eksklusif yang masih rendah di Kecamatan Wonoayu pada tahun 2015 menjadi landasan terbentuknya Kelompok Pendukung Air Susu Ibu (KP-ASI). Tujuan penelitian ini adalah untuk mengetahui perbedaan riwayat pemberian ASI eksklusif dan status gizi bayi 6-12 antara peserta KP-ASI dan non peserta KP-ASI. Penelitian ini adalah observasional analitik dengan desain penelitian cross sectional. Penelitian ini dilakukan di wilayah kerja Puskesmas Wonoayu dan Puskesmas Buduran Kabupaten Sidoarjo. Sampel penelitian diambil menggunakan metode stratified random sampling sebesar 36 ibu bayi 6-12 bulan peserta KP-ASI dan 36 ibu bayi 6-12 bulan non peserta KP-ASI. Pengumpulan data melalui wawancara dengan menggunakan kuesioner dan pengukuran antropometri pada bayi menggunakan length board dan baby scale. Analisis data penelitian ini adalah uji Chi-Square dan regresi logistik. Hasil penelitian menunjukkan bahwa terdapat perbedaan riwayat pemberian ASI eksklusif pada kedua kelompok $(\mathrm{p}=0,002)$ namun tidak terdapat perbedaan status gizi bayi $6-12$ bulan pada dua kelompok tersebut $(\mathrm{p}=0,547)$. Status pekerjaan $\mathrm{ibu}(\mathrm{p}=0,022, \mathrm{OR}=0,211)$ dan dukungan keluarga lain $(\mathrm{p}=0,015, \mathrm{OR}=0,195)$ menjadi variabel perancu selain pelaksanaan KP-ASI $(\mathrm{p}=0,032, \mathrm{OR}=3,701)$ yang dapat memberikan pengaruh terhadap riwayat pemberian ASI eksklusif. Dapat disimpulkan bahwa peserta KP ASI berpeluang 3,701 kali lebih besar untuk memberikan ASI eksklusif kepada bayinya dibanding ibu yang bukan peserta KP ASI ada perbedaan status gizi bayi 6-12 bulan pada kedua kelompok. Disarankan kepada Dinas Kesehatan Kabupaten Sidoarjo untuk mengembangkan dan mengaktifkan kembali pelaksanaan KP-ASI di wilayah lain agar dapat meningkatkan praktik pemberian ASI eksklusif.
\end{abstract}

Kata kunci: Kelompok Pendukung ASI (KP-ASI), perilaku pemberian ASI eksklusif, status gizi

\section{ABSTRACT}

Breast Milk is the best and nutritious food in early life for every infants born. Undernourishment in infants can cause growth and development disorders. The attainment of exclusive breastfeeding that still low in Wonoayu sub-district in 2015 becomes the base the formation of breastfeeding support group (KP-ASI). The aim of this study was to observe the difference of exclusive breastfeeding record and nutrition status of infants aged 6-12 months of KP-ASI participant and non KP-ASI participant. This research was an analytic observational with cross sectional design. This research was done in the working area at Wonoayu and Buduran Health Center, district Sidoarjo. The sample were taken using stratified random sampling, the sample size 36 mothers of infants 6-12 months from KP-ASI participants and 36 mothers of infants 6-12 months from the non KP-ASI participants. The data collection was interviewed by using questionnaire and anthropometry measurements by using length board and baby scale. Data analysis of the research was Chi-Square test and Logistic Regression. The result showed that there was significant difference exclusive breastfeeding record between groups $(p=0.002)$ but there was no difference in nutrition status of infants aged 6-12 months ( $p=0.547)$ in between both group. Mother employment status $(p=0.022, O R=0.211)$, other family support $(p=0.015, O R=0.195)$ becomes a confounding variable aside from implementation of KP-ASI $(p=0.032, O R=3.701)$ which influence exclusive breastfeeding record. The conclusion of this study was that KP-ASI participant have 3.701

Nur Hikmahwati, et al., MGI(2018) 33-40

DOI: $10.20473 /$ mgi.v13i1.33-40. 
times higher chance to give exclusive breastfeeding the their babies compared with non-KP ASI number there was no difference nutrition status of infants aged 6-12 months from both group it' is suggested for Public Health Service of Regency Sidoarjo to develop and reactivate implementation of breastfeeding support group in other district to improve the practice of exclusive breastfeeding.

Keywords: breastfeeding support group, exclusive breastfeeding practice, nutritional status

\section{PENDAHULUAN}

Masalah gizi kurang dan gizi buruk masih menjadi permasalahan di Indonesia yang dibuktikan dengan hasil Riskesdas pada tahun 2007, 2010 dan 2013 bahwa prevalensi gizi kurang (underweight) berturut turut adalah 18,4\%, 17,9\% dan $19,6 \%$. Kekurangan gizi pada periode emas 1000 hari kehidupan yaitu sejak janin sampai anak berumur dua tahun akan memengaruhi perkembangan fisik dan juga kecerdasan anak (Kemenkes RI, 2014). Selain asupan gizi yang inadekuat penyakit infeksi juga menjadi penyebab langsung terjadinya malnutrisi (Susilowati dan Kuspriyanto, 2016). Air susu ibu menjadi makanan pertama dan utama bagi bayi namun praktik pemberian ASI di Indonesia masih jauh dari yang diharapkan. Rendahnya angka cakupan pemberian ASI eksklusif di daerah perkotaan maupun pedesaan dipengaruhi oleh berbagai faktor. Kurangnya informasi dan rendahnya pengetahuan ibu terkait pemberian ASI eksklusif, banyaknya ibu bekerja yang beranggapan bahwa suatu hal yang sulit dilakukan jika bekerja dengan tetap memberikan ASI dan masih berkembangnya mitos dalam kehidupan sosial budaya di masyarakat juga turut memengaruhi perilaku pemberian ASI eksklusif (Yulierti, 2011).

Kesuksesan pemberian ASI eksklusif tidak hanya dipengaruhi oleh kesiapan ibu secara fisik maupun mentalnya dalam menyusui namun juga dipengaruhi oleh dukungan baik dari petugas kesehatan maupun dari keluarga (Berliana, 2014). Penelitian pada daerah pedesaan di Uganda membuktikan bahwa peer support dalam bentuk kunjungan dan memberikan dukungan dapat lebih mudah diterima dalam komunitas ibu menyusui, ibu merasa senang memiliki seseorang konselor sebaya yang dapat membantu mereka dengan berbagai masalah selama menyusui (Nankunda et al., 2006).
Data profil kesehatan Indonesia 2015 menyebutkan bahwa cakupan ASI eksklusif pada tahun 2015 sebesar 55\%, angka tersebut masih jauh dari target nasional ASI yaitu sebesar $80 \%$. Kabupaten Sidoarjo merupakan salah satu daerah di Indonesia dengan cakupan ASI eksklusif yang juga belum memenuhi target nasional, terbukti hanya sebesar $57,30 \%$ pada tahun 2015. Cakupan ASI eksklusif di Kabupaten Sidoarjo yang belum mencapai target disebabkan oleh berbagai kemungkinan seperti semakin banyaknya ibu yang bekerja untuk membantu perekonomian rumah tangga, penggunaan susu formula yang menjadi trend di masyarakat atau karena kurangnya pengetahuan ibu terkait pemenuhan gizi bayinya. Berbagai upaya yang digalangkan oleh Dinas Kesehatan setempat untuk meningkatkan cakupan ASI eksklusif yang lebih intensif, antara lain pelatihan konselor menyusui, pelatihan motivator ASI dan pembentukan Kelompok Pendukung ASI (KP-ASI) (Dinkes Sidoarjo, 2015). Kelompok Pendukung Ibu (KP-Ibu) adalah wadah bagi ibu menyusui untuk saling memberi dan menerima dukungan baik teknis, moral maupun emosional dengan cara bertukar pengalaman serta berdiskusi terkait kesehatan ibu dan anak khususnya seputar menyusui dan gizi yang difasilitasi atau dipandu oleh motivator ASI (Mercy Corps, 2011)

Tujuan utama kelompok pendukung adalah untuk meningkatkan informasi dan pengetahuan serta membantu dalam mengembangkan keterampilan anggota kelompok sehingga mampu mewujudkan perilaku positif (Bensley et al., 2009). KP-ASI dinilai akan memberikan pengaruh yang lebih efektif untuk memberikan pendidikan kesehatan pada anggotanya. Pendidikan yang dimaksud bukanlah sebagai pengajaran dengan metode pembelajaran satu arah seperti penyuluhan, ceramah atau pemberian leaflet dan poster dimana sasaran lebih banyak menerima dan kurang 
aktif terlibat dalam interaksi yang timbal balik (Subargus, 2011).

Dalam kegiatan KP-ASI para anggota mempunyai ruang yang lebih luas untuk berpartisipasi aktif dalam proses pendidikan kesehatan (Ichsan et al., 2015 ).

Menurut Black et al. (2010), pembelajaran harus sekedar dari menyebarkan informasi namun pendidik kesehatan juga harus bisa memberi kesempatan pada peserta didik untuk belajar secara aktif dan berpikir kritis dalam mendapatkan pengetahuan yang kemudian akan menghasilkan suatu tindakan. Penelitian ini bertujuan untuk melihat pengaruh program KP-ASI terhadap riwayat pemberian ASI eksklusif dan status gizi bayi 6-12 bulan.

\section{METODE}

Penelitian ini merupakan penelitian observasional analitik dengan desain cross sectional yang dilaksanakan di wilayah kerja Puskesmas Buduran dan wilayah kerja Puskesmas Wonoayu Kabupaten Sidoarjo pada bulan Mei-Juli 2017. Populasi dari penelitian ini adalah semua ibu yang mempunyai bayi usia $6-12$ bulan di wilayah kerja Puskesmas Buduran dan Puskesmas Wonoayu Kabupaten Sidoarjo. Pemilihan sampel dalam penelitian ini menggunakan teknik stratified random sampling dengan cara membagi populasi ke dalam kelompok homogen yang disebut strata antara peserta KP-ASI dan non KP-ASI dan sampel diambil secara acak dari setiap desa. Besar sampel sebear 72 kemudian dibagi berdasarkan jumlah strata menjadi 36 sampel pada masing-masing kelompok, yaitu yang mengikuti kegiatan KPASI dan yang tidak mengikuti kegiatan KP-ASI. Variabel bebas dalam penelitian ini adalah KP-ASI sedangkan yang termasuk variabel terikat adalah riwayat pemberian ASI eksklusif serta status gizi bayi $6-12$ bulan. Terdapat variabel yang dijadikan sebagai variabel perancu dalam penelitian ini yaitu umur ibu, pendidikan, pekerjaan, dukungan suami dan dukungan keluarga lain.

Data yang dikumpulkan adalah terkait kepesertaan KP-ASI, riwayat pemberian ASI eksklusif, dukungan suami, dukungan keluarga dan karakteristik ibu yang meliputi usia, pendidikan terakhir dan status pekerjaan yang diperoleh melalui wawancara menggunakan kuesioner, sedangkan indeks penentuan status gizi yang digunakan adalah indeks Berat Badan Panjang Badan dengan data antropometri meliputi berat badan dan panjang badan diukur menggunakan alat pengukur baby scale dan length board. Teknik analisis data yang digunakan adalah uji beda dua kelompok dengan uji Chi-Square dan uji regresi logistik untuk melihat pengaruh variabel lain yang dianggap perancu dan variabel bebas yang telah ditetapkan dan dapat dimungkinkan memengaruhi variabel terikat dengan tingkat kemaknaan $p<0,05$. Penelitian ini telah memperoleh persetujuan dari komite etik Fakultas Kesehatan Masyarakat Universitas Airlangga Surabaya No: 294-KEPK.

\section{HASIL DAN PEMBAHASAN}

Karakteristik ibu sebagai responden penelitian di wilayah kerja Puskesmas Wonoayu dan Puskesmas Buduran yang diteliti meliputi umur ibu, pendidikan terakhir dan status pekerjaan ibu. Gambaran karakteristik ibu dalam penelitian dapat dilihat pada Tabel 1. Diketahui bahwa distribusi responden berdasarkan umur ibu menunjukkan proporsi tertinggi adalah umur 20-35 tahun yaitu pada ibu KP-ASI sebesar $80,5 \%$ dan pada ibu non KP-ASI sebesar-77,8\%. Sebagian besar ibu KP-ASI termasuk dalam kategori umur 20-35 tahun dikarenakan sasaran utama KP-ASI adalah ibu dengan kategori reproduksi sehat, baik yang sedang menyusui ataupun yang sedang mempersiapkan diri untuk menyusui bayinya. Pendidikan terakhir ibu pada kelompok KP-ASI tertinggi $(69,4 \%)$ adalah tamat SMA begitu juga pada ibu non KP-ASI $(61,1 \%)$, sehingga tingkat pendidikan terakhir kedua kelompok relatif tidak berbeda jauh. Banyaknya pendidikan ibu KP-ASI yang telah tamat SMA menggambarkan potensi bahwa ibu dapat lebih mudah menerima informasi dalam proses pembelajaran untuk meningkatkan pengetahuan relatif sama. Banyaknya pendidikan ibu KP-ASI yang telah tamat SMA menggambarkan potensi bahwa ibu dapat lebih mudah menerima informasi dalam proses pembelajaran untuk meningkatkan pengetahuan mereka. Distribusi status pekerjaan tertinggi pada kedua kelompok 
Tabel 1. Distribusi Karakteristik Responden di Wilayah Puseksmas Wonoayu dan Puskesmas Buduran Kabupaten Sidoarjo Tahun 2017

\begin{tabular}{|c|c|c|c|c|}
\hline \multirow[t]{2}{*}{ Karakteristik Responden } & \multicolumn{2}{|c|}{$\begin{array}{c}\begin{array}{c}\text { KP-ASI } \\
n=36\end{array} \\
\text { nes }\end{array}$} & \multicolumn{2}{|c|}{$\begin{array}{c}\text { non KP-ASI } \\
n=36\end{array}$} \\
\hline & $\mathrm{n}$ & $\%$ & $\mathbf{n}$ & $\%$ \\
\hline \multicolumn{5}{|l|}{ Umur Ibu } \\
\hline$<20$ tahun & 1 & 2,7 & 4 & 11,1 \\
\hline 20-35 tahun & 29 & 80,5 & 28 & 77,8 \\
\hline$>35$ tahun & 6 & 16,7 & 4 & 11,1 \\
\hline \multicolumn{5}{|l|}{ Pendidikan Ibu } \\
\hline Tamat SD & 1 & 2,8 & 3 & 8,3 \\
\hline Tamat SMP & 6 & 16,7 & 2 & 5,6 \\
\hline Tamat SMA & 25 & 69,4 & 22 & 61,1 \\
\hline Tamat Perguruan Tinggi & 4 & 11,1 & 9 & 25 \\
\hline \multicolumn{5}{|l|}{ Status Pekerjaan Ibu } \\
\hline Bekerja & 8 & 22,2 & 10 & 27,8 \\
\hline Tidak Bekerja & 28 & 77,8 & 26 & 72,2 \\
\hline
\end{tabular}

adalah tidak bekerja yaitu pada ibu KP-ASI sebesar $77,8 \%$ dan pada ibu non KP-ASI sebesar 72,2\%. Sebagian besar ibu KP-ASI adalah ibu rumah tangga yang mempunyai waktu luang lebih banyak terutama untuk hadir dalam kegiatan KP-ASI.

Proses pemberian ASI eksklusif adalah memberi ASI saja tanpa tambahan makanan atau minuman lain sampai bayi memasuki usia 6 bulan.

Tabel 2 menunjukkan lebih banyak ibu KP-ASI yang memiliki riwayat pemberian ASI eksklusif (72,5\%) dibandingkan dengan yang tidak ASI eksklusif, (27,85\%). Pada ibu non KP-ASI sejumlah $63,9 \%$ memiliki riwayat pemberian ASI tidak eksklusif. Jumlah ini lebih banyak dibandingkan ibu yang memberikan ASI eksklusif pada bayinya yaitu hanya sebesar $36,15 \%$.

Berdasarkan hasil wawancara dengan responden ditemukan beberapa kendala yang dirasa ibu menjadi penghambat dalam proses pemberian ASI eksklusif. Pengetahuan yang terbatas tentang menyusui dan pemahaman gizi pada bayi, kurangnya kepercayaan diri dari ibu, dan kondisi pikiran ibu yang stress menyebabkan kegiatan menyusui menjadi semakin sulit. Selain itu semakin banyaknya produk susu formula yang beredar di pasaran menjadikan pilihan kemudahan bagi ibu dalam memberikan susu kepada bayinya meskipun pada kenyataannya tidak akan ada produk susu formula yang dapat menandingi komposisi zat gizi ASI. Hasil uji
Chi-Square dengan nilai signifikasi $\mathrm{p}=0,001$ berarti menunjukkan bahwa ada perbedaan proporsi yang bermakna antara riwayat pemberian ASI eksklusif antara ibu KP-ASI dan ibu non KP-ASI sehingga terdapat pengaruh KP-ASI terhadap riwayat pemberian ASI eksklusif. Pembentukan program KP-ASI di wilayah Puskesmas Wonoayu terjadi karena wilayah tersebut menjadi salah satu wilayah dengan cakupan ASI eksklusif yang rendah di Kabupaten Sidoarjo. KP-ASI dianggap mempunyai dampak positif karena dapat meningkatkan capaian ASI eksklusif di wilayah Puskesmas Wonoayu terbukti berdasarkan data Profil Puskesmas Wonoayu pada tahun 2016 cakupan ASI eksklusif di wilayah tersebut sebesar $59,96 \%$ dan setelah adanya program KP-ASI, cakupan ASI eksklusif di Kecamatan Wonoayu meningkat sebesar 70,1\%.

Sejalan dengan penelitian yang dilakukan oleh Pawestri, et al. (2012) di Puskesmas Pandak 1 Bantul bahwa kegiatan KP-Ibu dapat memberikan pengaruh kepada ibu untuk memberikan ASI eksklusif kepada bayinya. Penelitian lain yang dilakukan oleh Nurrohmah, et al. (2014) di wilayah kerja Puskesmas Ngoresan Surakarta juga menunjukkan bahwa KP-Ibu mempunyai peran secara nyata terhadap perilaku pemberian ASI eksklusif. Pendidikan kesehatan dalam bentuk kelompok pendukung dapat menjadi alat yang kuat untuk mengubah atau memodifikasi perilaku manusia.

Tabel 2. Perbedaan Riwayat Pemberian ASI Eksklusif dan Status Gizi Bayi 6-12 Bulan KP-ASI dan Non KP-ASI di Wilayah Kerja Puskesmas Wonoayu dan Puskesmas Buduran Tahun 2017

\begin{tabular}{|c|c|c|c|c|c|}
\hline & \multicolumn{4}{|c|}{ Kepesertaan KP-ASI } & \multirow{3}{*}{$\mathbf{p}$} \\
\hline & \multicolumn{2}{|c|}{ KP-ASI } & \multicolumn{2}{|c|}{ Non KP-ASI } & \\
\hline & n & $\%$ & $\mathbf{n}$ & $\%$ & \\
\hline \multicolumn{5}{|c|}{ Riwayat Pemberian ASI Eksklusif } & \multirow{3}{*}{0,002} \\
\hline ASI Eksklusif & 26 & 72,2 & 13 & 36,1 & \\
\hline Tidak ASI Eksklusif & 10 & 27,8 & 23 & 63,9 & \\
\hline \multicolumn{6}{|l|}{ Status Gizi Bayi } \\
\hline Sangat Kurus & 0 & 0 & 1 & 2,8 & \\
\hline Kurus & 3 & 8,3 & 4 & 11,1 & 0,547 \\
\hline Normal & 33 & 91,7 & 31 & 86,1 & \\
\hline
\end{tabular}


Seseorang anggota kelompok pendukung mendapatkan kekuatan intervensi ketika mereka mampu memahami perilaku seseorang dan mampu menyadari bahwa mereka berada pada situasi yang sama dengan anggota lainnya (Bensley et al., 2009). Orang yang berada dalam situasi yang sama cenderung akan lebih mudah untuk berempati dan memberikan informasi dan pengalamannya kepada orang lain (Mercy Corps, 2008). Informasi dan pengalaman yang diterima ibu dalam mengikuti

KP-ASI dapat menghasilkan pengetahuan yang akan membentuk sikap keyakinan untuk melakukan perilaku pemberian ASI eksklusif (Haryono dan Setianingsih, 2014). Program KP-ASI memengaruhi anggota melalui berbagai kegiatan edukasi di dalamnya, seperti kegiatan konseling, tanya jawab dan penyampaian informasi yang diberikan oleh bidan maupun motivator KP-ASI di setiap kelompok. Selain itu dalam kegiatan KP-ASI juga terdapat interaksi antar anggota untuk bertukar pengalaman baik pengalaman tentang keberhasilan maupun kesulitan yang dihadapi selama proses menyusui.

Berdasarkan Tabel 2 juga dapat diketahui bahwa kedua kelompok memiliki proporsi status gizi yang hampir sama yaitu sebagian besar masuk dalam kategori status gizi normal. Bayi KP-ASI dengan status gizi normal sebesar 91,7\% sedangkan bayi dengan status gizi kurus hanya sebesar 8,3\%. Bayi non KP-ASI dengan status gizi normal sebesar $86,1 \%$ sedangkan dengan status gizi kurus dan sangat kurus sebesar 11,1\% dan 2,8\%. Hasil uji Chi-Square dengan nilai signifikansi $\mathrm{p}=0,547$ yang berarti menunjukkan bahwa tidak terdapat perbedaan proporsi status gizi bayi antara bayi KP-ASI dan bayi non KP-ASI. Status gizi adalah keadaan tubuh yang merupakan hasil akhir dari keseimbangan antara zat gizi yang masuk ke dalam tubuh dan utilisasinya Achmad, (2009) dalam penelitian ini indeks penentuan status gizi yang digunakan adalah indeks BB/PB. Indeks $\mathrm{BB} / \mathrm{PB}$ merupakan indikator yang baik untuk menilai status gizi saat ini dan merupakan indeks yang independen terhadap umur serta dapat membedakan proporsi badan gemuk, normal dan kurus (Supariasa et al., 2012).
Tujuan utama program KP-ASI di wilayah kerja Puskesmas Wonoayu adalah memberikan dukungan kepada ibu bayi dan keluarganya untuk tetap memberikan ASI eksklusif sampai umur 6 bulan. Topik dalam setiap pertemuan kegiatan KP-ASI adalah seputar ASI eksklusif dan menyusui namun tidak menutup kemungkinan untuk membahas topik terkait MP-ASI ataupun gizi bayi, mengingat peserta dalam program KP-ASI ini tidak hanya bayi usia $0-6$ bulan saja tetapi juga terbuka untuk bayi 6-24 bulan yang mempunyai keinginan mengoptimalkan perilaku menyusui hingga umur 2 tahun.

Dalam penelitian ini sebagian besar bayi, baik yang mengikuti program KP-ASI maupun tidak mengikuti KP-ASI memiliki status gizi yang sesuai untuk tumbuh kembangnya. Pertumbuhan dan perkembangan yang pesat pada bayi akan terjadi pada masa periode emas yaitu di 1000 hari pertama kehidupan. Periode emas dapat diwujudkan apabila pada masa ini bayi memperoleh asupan gizi yang sesuai untuk tumbuh kembang optimal. Hasil penelitian menunjukkan bahwa tidak ada pengaruh KP-ASI terhadap status gizi bayi 6-12 bulan. Hal tersebut memperlihatkan bahwa perubahan status gizi memerlukan beberapa faktor yang akan saling memengaruhi. Faktor yang dapat memengaruhi status gizi seseorang secara langsung adalah asupan makanan dan penyakit infeksi, sedang faktor yang tidak langsung memengaruhi antara lain ketersediaan pangan rumah tangga, pola pengasuhan dan ketersediaan pelayanan kesehatan (UNICEF, 2013).

Penelitian oleh Badan Kesehatan Dunia (WHO) menyebutkan bahwa memberikan ASI hingga anak berumur 2 tahun dapat menurunkan angka kematian anak yang disebabkan oleh penyakit diare dan infeksi saluran napas akut oleh karena itu ASI mempunyai peran untuk melindungi bayi dari penyakit infeksi (IDAI, 2008). Dalam sebuah penelitian terkait pengaruh kelompok pendukung di negara berpenghasilan rendah dan menengah menyatakan bahwa kelompok pendukung secara signifikan dapat meningkatkan durasi dalam pemberian ASI eksklusif dan menurunkan angka kejadian diare 
Tabel 3. Faktor-Faktor yang Berpengaruh terhadap Riwayat Pemberian ASI Eksklusif di Wilayah Kerja Puskesmas Wonoayu dan Puskesmas Buduran Tahun 2017

\begin{tabular}{lcccl}
\hline \multicolumn{1}{c}{ Variabel } & B & $\mathbf{E x p}(\mathbf{B})$ & $\mathbf{P}$ & Keterangan \\
\hline KP-ASI & 1,309 & 3,701 & 0,032 & Berpengaruh \\
Pekerjaan ibu & $-1,555$ & 0,211 & 0,022 & Berpengaruh \\
Dukungan Suami & 0,232 & 0,793 & 0,750 & Tidak Berpengaruh \\
Dukungan Keluarga Lain & $-1,635$ & 0,195 & 0,015 & Berpengaruh \\
\hline
\end{tabular}

(Sudfeld et al., 2012) Penyakit infeksi dan asupan makanan akan saling memengaruhi status gizi bayi namun dalam penelitian ini terdapat keterbatasan peneliti dalam melihat dan menilai berbagai faktor yang dapat memengaruhi status gizi bayi secara langsung.

Hasil penelitian ini sejalan dengan penelitian yang dilakukan di Puskesmas Banguntapan Kabupaten Bantul Daerah Istimewa Yogyakarta yang menunjukkan bahwa tidak ada pengaruh kelompok pendukung ibu (KP-Ibu) terhadap perilaku tentang ASI dan MP-ASI serta status gizi balita usia 6-24 bulan (Dewi, 2015).

Berdasarkan analisis bivariat dengan uji beda menunjukkan bahwa terdapat pengaruh KP-ASI terhadap riwayat pemberian ASI eksklusif sehingga dalam penelitian ini dilakukan analisis multivariat yaitu uji regresi logistik untuk menganalisis faktor-faktor yang memengaruhi riwayat pemberian ASI eksklusif. Hasil uji regresi logistik dapat dilihat pada Tabel 3. Variabel yang dimasukkan dalam model adalah variabel dummy yang sebelumnya sudah dianalisis bivariabel dan mempunyai nilai $\mathrm{p}<0,25$ yaitu variabel kepesertaan KP-ASI yang dikategorikan menjadi mengikuti dan tidak mengikuti, pekerjaan ibu yang dikategorikan menjadi bekerja dan tidak bekerja, serta dukungan suami dan dukungan keluarga lain yang dikategorikan menjadi mendukung dan tidak mendukung.

Hasil analisis regresi logistik menunjukkan bahwa dari 4 variabel yang dimungkinkan mempunyai pengaruh terhadap riwayat pemberian ASI eksklusif adalah kepesertaan KP-ASI $(\mathrm{p}=0,032)$, pekerjaan ibu $(\mathrm{p}=0,022)$ dan dukungan keluarga lain $(\mathrm{p}=0,015)$. Besarnya pengaruh ditunjukkan dengan $\operatorname{Exp}(\mathrm{B})$ atau Odd Ratio (OR). Variabel KP-ASI dengan OR 3,701 maka ibu yang mengikuti KP-ASI berpeluang untuk dapat memberikan ASI eksklusif 3,701 kali lipat dibandingkan ibu yang tidak mengikuti KP-ASI. Hal tersebut membuktikan bahwa program KP-ASI di wilayah Puskesmas Wonoayu sudah berdampak terhadap pemberian ASI eksklusif pada bayi.

Kerja kelompok pendukung tidak hanya sekedar memberikan informasi agar dapat meningkatkan pengetahuan namun anggota kelompok pendukung yang berpartisipasi dapat belajar dari mendengar, mengamati, mencoba perilaku baru, menerima umpan balik dan merasakan dukungan dari anggota lain (Bensley, et al., 2009). Informasi yang diberikan pada anggota KP-ASI memberikan dampak yang nyata terhadap pengetahuan seseorang. Pengetahuan, keyakinan dan emosi memegang peranan penting dalam pembentukan sikap. Ibu yang mengikuti kegiatan KP-ASI mempunyai peluang besar untuk memperoleh pengetahuan yang baik tentang ASI yang kemudian dapat memengaruhi sikap dan perilaku mereka dalam memberikan ASI eksklusif pada anaknya.

Pemberian ASI eksklusif memang tidak selalu didasari oleh pengetahuan saja karena terdapat banyak faktor yang dapat memengaruhi, namun minimal jika didasari pengetahuan yang cukup dan sikap yang positif akan membentuk perilaku positif relatif lebih lama Maulana (2009).

Pekerjaan ibu menjadi faktor protektif untuk perilaku pemberian ASI eksklusif $(\mathrm{OR}=0,211)$. Ibu yang tidak bekerja berpeluang untuk memberikan ASI eksklusif dibandingkan ibu yang bekerja. Sebagian besar ibu KP-ASI sebanyak 28 orang berstatus sebagai ibu rumah tangga sehingga akan berpeluang mempunyai waktu yang lebih banyak untuk memberikan ASI eksklusif secara optimal. 
Ibu KP-ASI yang tidak bekerja juga akan lebih berpeluang untuk mengikuti kegiatan secara rutin setiap bulannya. Berbeda hal nya dengan ibu yang bekerja, yaitu kesibukan mereka membuat waktu untuk mengikuti berbagai kegiatan kesehatan bayi dan anak seperti KP-ASI di wilayahnya juga akan sedikit. Sebagian dari mereka menitipkan bayinya kepada orang tua atau pun kerabatnya selama bekerja. Kesadaran mereka untuk memompa dan menyimpan ASI nya untuk diberikan kepada bayi saat ibu tidak berada di rumah juga cukup rendah, sehingga peluang untuk memberikan susu formula sebagai alternatif dalam memenuhi kebutuhan asupan bayinya akan semakin besar namun dalam penelitian ini peneliti tidak dapat menunjukkan banyaknya jumlah ibu bekerja yang lebih memilih memberikan susu formula ataupun memompa dan menyimpan ASInya karena keterbatasan penelitian.

Dukungan dari keluarga menjadi faktor yang memengaruhi perilaku ASI Ekslusif. Menurut Oktalina et al. (2016) dukungan informasi tentang ASI eksklusif dari keluarga akan mendorong ibu untuk dapat memberikan ASI eksklusif dibandingkan dengan ibu yang tidak mendapatkan informasi tentang ASI dari keluarganya. Ketika keluarga menyadari bahwa ASI tidak hanya bermanfaat untuk bayi tetapi juga untuk ibu, maka keluarga akan menyarankan ibu untuk menyusui secara eksklusif. Dukungan dari keluarga termasuk dukungan psikologis dalam bentuk memotivasi ibu untuk memberikan ASI saja kepada bayinya sampai umur 6 bulan.

Sasaran KP-ASI di wilayah kerja Puskesmas Wonoayu bukan hanya ibu dan bayi. Hal tersebut dimaksudkan agar ibu juga dapat memperoleh dukungan yang positif di lingkungan rumahnya selama proses menyusui, karena ibu yang menghadapi tekanan selama proses menyusui akan merasa lebih tenang ketika mendapat saran yang benar terkait menyusui dari keluarga lain. Ibu juga akan menjadi lebih percaya diri untuk memberikan ASI eksklusif kepada bayinya

\section{KESIMPULAN DAN SARAN}

Kelompok Pendukung ASI (KP-ASI) dapat meningkatkan peluang pemberian ASI eksklusif sebesar 3,701 kali lebih besar. Selain kepesertaan KP-ASI, status pekerjaan ibu dan dukungan keluarga lain menjadi variabel perancu yang mempunyai pengaruh parsial dengan peluang masing-masing sebesar 0,211 dan 0,195 lebih besar untuk meningkatkan pemberian ASI eksklusif. KP-ASI tidak memberikan pengaruh terhadap status gizi bayi 6-12 bulan karena sebagian besar bayi peserta KP-ASI maupun non KP-ASI memiliki status gizi normal. Disarankan kepada Dinas Kesehatan Kabupaten Sidoarjo untuk dapat mengaktifkan kembali dan mengembangkan pelaksanaan KP-ASI pada wilayah lain di Kabupaten Sidoarjo agar dapat meningkatkan cakupan ASI eksklusif di Kabupaten Sidoarjo sesuai target sebesar $80 \%$ sehingga bayi dapat mencapai status gizi yang optimal pada 1000 hari pertama kehidupan.

\section{DAFTAR PUSTAKA}

Bensley, R. J., Brookins, J., \& Fisher. (2009). Metode pendidikan kesehatan masyarakat Edisi 2. Jakarta: Buku Kedokteran ECG.

Black, J.M, Furney, S.R., Graf, H. M., \& Nolte, A.E. (2010). Philosophical foundations of health education. $9^{\text {th }}$ Edition. United States of America: Jossey-bass.

Berliana, F. (2014). Buku pintar ASI dan menyusui. Yogyakarta: Noura Publishing.

Dinas Kesehatan Kabupaten Sidoarjo. (2015). Profil kesehatan Kabupaten Sidoarjo tahun 2014. Sidoarjo: Dinas Kesehatan.

Dewi, D.P. (2015). Pengaruh kelompok pendukung (KP) ibu terhadap pengetahuan dan perilaku ibu dalam pemberian ASI dan MP ASI serta status gizi balita 6-24 bulan. Hasil Penelitian dan Pengabdian LPPMUniversitas Muhammadiyah Purwokerto 11-17. Diakses dari http://download. portalgaruda.org.

Haryono, R. \& Setianingsih, S. (2014). Manfaat ASI eksklusif untuk buah hati. Yogyakarta: Gosyen Publishing.

IDAI. (2008). Bedah ASI. Jakarta: Balai Penerbit FKUI.

Ichsan, B., Salimono, H., \& Soebijanto, H.A.A. (2015). Keefektifan program kelompok pendukung ibu dalam mengubah perilaku ibu menyusui. Jurnal Kesehatan Masyarakat, 10(2), 186-194. Diakses dari http:journal. unnes.ac.id. 
Kemenkes, RI. (2013). Riset Kesehatan Dasar Tahun 2013. Jakarta: Balitbang Kementerian Kesehatan RI.

Kemenkes RI. (2014). INFODATIN (Pusat Data dan Informasi Kementerian Kesehatan RI). Jakarta Selatan: Kementerian Kesehatan RI.

Kemenkes, RI. (2015). Profil kesehatan Indonesia 2015. Jakarta: Balitbang Kementerian Kesehatan RI.

Maulana, H. 2009. Promosi kesehatan. Jakarta: EGC.

Mercy Corps-USAID. (2008). 10 Topik umum diskusi kelompok pendukung ibu. Jakarta: Mercy Corps.

Mercy Corps Indonesia. (2011). Panduan pelatihan pembina motivator kelompok pendukung ibu Jakarta. Jakarta: Mercy Corps.

Nankunda, J., Tumwina, J.K., Soltvedt, A., Semiyaga, N., Ndeezi, G., \& Tylleskar, T. (2006). Community based peer counselors for support of exclusive breastfeeding: experiences from rural Uganda. International Breastfeeding Journal 1(19).

Nurrohmah, A., Prawitasari, S., \& Artanty, W. (2015). Role of mother support group (KP$\mathrm{Ibu}$ ) on behavior of exclusive breastfeeding in work area primary health care (puskesmas) of Ngoresan Surakarta. International Journal of Research In Medical Sciences. 3 (1) 141-149. Diakses dari http://www.msjonline.org.

Oktalina, O., Muniroh, L., \& Adiningsih S. 2015. Hubungan Dukungan Suami dan Dukungan
Keluarga dengan Pemberian ASI Eksklusif pada Ibu Anggota Kelompok Pendukung ASI (KP-ASI). Jurnal Media Gizi Indonesia. 10 (1). 64-70. Diakses dari http://mediagizipangan. org.

Pawestri, Nila., \& Sulistyaningsih. (2012). Efektivitas peran kelompok pendukung ibu dalam pemberian ASI eksklusif di Puskesmas Pandak 1 Bantul. Jurnal Kebidanan dan Keperawatan. 8(1) 52-62 Diakses dari http:// digilib.unisayogya.ac.id.

Sediaoetama, Achmad, D. (2009). Ilmu gizi. Jakarta: Dian Rakyat.

Sudfeld, C.R., Fawzi, W.W., \& Lahariya, C. (2012). Peer support and exclusive breastfeeding duration in low and middle income countries: a systematic review and meta-analysis. Journals PLOS 7(9). Diakses dari http://Journals.plos. org.

Supariasa, I.D.N., Bakri, B., \& Fajar, I. (2012). Penilaian status gizi (Edisi Revisi). Jakarta: Penerbit Buku Kedokteran ECG.

Susilowati \& Kuspriyanto. (2016). Gizi dalam Daur Kehidupan. Bandung: Refika aditama.

Subargus, A. (2011). Promosi kesehatan melalui pendidikan kesehatan masyarakat. Yogyakarta: Gosyen publishing.

United Nations Children's Fund. 2013. Improving child nutrition. UNICEF.

Yulierti, N. (2010). Keajaiban ASI makanan terbaik untuk kesehatan dan kecerdasan. Yogyakarta: Penerbit Andi Offset. 